\title{
An Alternative Healing Method for Grafted Tomato Transplants: The Effect of Light Exclusion and Substrate Temperature on Plant Survival and Growth
}

\author{
Kristine M. Lang ${ }^{1}$, Ajay Nair ${ }^{2}$, and Alexander G. Litvin ${ }^{3}$
}

ADDITIONAL INDEX wORDs. Graft union, healing chamber, relative humidity, rootstock, scion, Solanum lycopersicum

SUMMARY. The use of tomato (Solanum lycopersicum) grafting is gaining traction across the United States, but small-scale growers face the challenge of creating optimum postgrafting healing conditions. The practice of blocking light for a period of 2 to 4 days while maintaining high humidity is commonly recommended for healing grafted tomato transplants; however, research is exploring alternatives to this practice. The present study investigated a low-input healing method for grafted tomato transplants with a specific focus on light and the use of propagation heat mats to regulate substrate and healing chamber air temperatures during the 7-day healing process. We hypothesized that 4 days of light exclusion and the use of propagation heat mats would improve grafted tomato transplant survival and growth. 'Cherokee Purple' was used as the scion and 'RST-04-106-T' was used as the rootstock. The whole plot factor was heat [propagation mats set at $80{ }^{\circ} \mathrm{F}$ (heat) or no propagation mat (no heat)] and the subplot factor was light exclusion $(0,4$, or 6 days of dark). The highest survival rate among treatments was $97 \%$ in 0 days of dark with no heat treatment; survival decreased to $84 \%$ in 4 and 6 days of dark with no heat treatments. The plant survival rate was $96 \%$ with 0 days of dark and heat treatment; however, the survival rates were $63 \%$ and $45 \%$ for the 4 - and 6 -day dark treatments, respectively. The scion stem diameter was largest for transplants grown in 0 days of dark, but there was no difference in stem diameter due to heat treatments. There were no differences among scion or rootstock biomasses due to heat or light treatments. These results demonstrate that propagation mats set at $80{ }^{\circ} \mathrm{F}$ to regulate the substrate temperature were detrimental to grafted transplant survival under extended periods of light exclusion. However, this finding creates the basis to explore lower levels of substrate temperature modification. Our work also indicates that light exclusion may not be necessary for healing grafted tomato plants regardless of root-zone temperature treatments. Future work should examine the interactions of various substrate and air temperatures under full light conditions and their effects on grafted tomato transplant survival and growth. This work contributes to the ongoing research of how to optimize low-input healing methods that may be readily adopted by small-scale tomato growers.

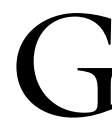
rafted tomato transplants (Solanum lycopersicum) have become an important production tool for vegetable growers within the United States (Grieneisen et al., 2018; Masterson et al., 2016a; Meyer, 2016; Rivard and Louws, 2008). Vegetable grafting of both solanaceous and cucurbit crops first emerged as an important method of overcoming soil-borne diseases (Lee et al., 2010), and the practice of grafting has been adopted on a larger scale in the United States within the past two decades (Albacete et al., 2015; Kubota et al., 2008). Grafting has been shown to be an effective tool for increasing farm profitability (Barrett et al., 2012; Rysin and Louws, 2015; Rysin et al., 2015).
The benefits of vegetable grafting include increasing the marketable yield, improving resistance to soil-borne disease, and overcoming adverse environmental conditions (Albacete et al., 2015; Kubota et al., 2008).

Specifically, vegetable growers in the midwestern United States have expressed interest in learning more about using grafted transplants on their farms (Masterson et al., 2016b; Meyer et al., 2017). Researchers are working to break down the barriers to adopting grafting to provide growers with improved recommendations regarding how to perform grafting and how to manage plants immediately postgrafting (Bausher, 2013; Buajaila et al., 2018; Johnson and Miles, 2011; Masterson et al., 2016b; Meyer et al., 2017).
Tomato plants are approachable for growers to graft on-farm due to the simplicity of the splice grafting method and the potentially high survival rate of transplants postgrafting (Buajaila et al., 2018). When proper grafting techniques are used, grafted tomato transplant survival after healing has been shown to exceed $97 \%$ (Bausher, 2013; Johnson and Miles, 2011). A skilled worker can graft between 300 and 500 plants per hour using the splice grafting method (Kubota et al., 2008), making onfarm grafting for small-scale production a relatively expeditious process. However, reports indicate the postgrafting healing process requires $\approx 1$ week inside a healing chamber and management of relative humidity ( $\mathrm{RH}$ ), light, and temperature (Bie et al., 2017; Lee et al., 2010; Rivard and Louws, 2011).

Healing chamber designs vary greatly, but the general structure for medium-scale to small-scale operations is a rigid frame fully enclosed by plastic sheeting (Lee et al., 2010; Masterson et al., 2016b; Rivard and Louws, 2011). This plastic may be semi-transparent (Lee et al., 2010) or opaque (Bie et al., 2017; Rivard and Louws, 2011).

Maintenance of humidity in the healing chamber is typically achieved through the use of commercial humidifiers (Masterson et al., 2016b; Wei et al., 2018), filling the bottom of the chamber with water (Masterson et al., 2016b; Rivard and Louws, 2011), or misting plants by hand using a spray bottle (Johnson and Miles, 2011). The recommendation is that grafted transplants should be kept at high $\mathrm{RH}$ between $80 \%$ to $100 \%$ for at least the first $4 \mathrm{~d}$ postgrafting (Kubota et al., 2008; Rivard and Louws, 2011). Recent work by Wei et al. (2018) found that $97 \%$ to $98 \% \mathrm{RH}$ is optimal for the healing of grafted tomatoes. Buajaila et al. (2018) conducted a trial of small-scale healing chambers with a target rate of $100 \%$ $\mathrm{RH}$ that resulted in an actual average RH ranging from $96 \%$ to $98 \%$ and the highest plant survival rate.

Light levels within the healing chamber have an important role in the graft healing process (Buajaila et al., 2018). Standard recommendations for healing grafted vegetable transplants include blocking all light within the chamber for the first 2 to 
$4 \mathrm{~d}$ postgrafting (Hartmann et al., 2010; Rivard and Louws, 2011). Alternatively, Kubota et al. (2008) suggested the use of low-light conditions instead of complete light exclusion. Recent research has focused on varying methods of achieving and maintaining low-light conditions within healing chambers (Buajaila et al., 2018; Johnson and Miles, 2011; Masterson et al., 2016b; Meyer et al., 2017). After testing the effects of available light reduced to $0 \%, 25 \%$, and $50 \%$ on grafted tomato transplants healed in small-scale chambers, Buajaila et al. (2018) suggested that the management of $\mathrm{RH}$ may be more important than the strict management of light level. Studies demonstrating high plant survival rates with only $50 \%$ light reduction (Buajaila et al., 2018; Masterson et al., $2016 \mathrm{~b}$ ) indicate to the need to measure the effects of no light exclusion on grafted tomato transplant healing.

The suggested optimum healing chamber air temperature varies; 27 to $28{ }^{\circ} \mathrm{C}$ has been recommended for general vegetable graft healing (Kubota et al., 2008) and 21 to $27^{\circ} \mathrm{C}$ has been recommended for tomato graft healing (Rivard and Louws, 2011). Johnson and Miles (2011) suggested that tomato transplants may be more tolerant of wider fluctuations in $\mathrm{RH}$ and temperature compared with grafted watermelon (Citrullus lanatus) and eggplant (Solanum melongena)

Received for publication 10 Apr. 2020. Accepted for publication 2 Sept. 2020.

Published online 5 October 2020.

${ }^{1}$ Department of Horticulture, Iowa State University, 260 Horticulture Hall, Ames, IA 50011

${ }^{2}$ Department of Horticulture, Iowa State University, 145 Horticulture Hall, Ames, IA 50011

${ }^{3}$ Department of Horticultural Science, North Carolina State University, 105 Kilgore Hall, Raleigh, NC 27695

We thank the U.S. Department of Agriculture North Central Sustainable Agriculture Research and Education for the Professional Development Grant (ENC17-161) that supported this research and extension project. We also thank our undergraduate research assistants and First-Year Honors Program students for support with transplant grafting, data collection, and sample analysis.

K.M.L. is a PhD Candidate.

A.N. is an Associate Professor.

A.G.L. is a Postdoctoral Research Scholar.

A.N. is the corresponding author. E-mail: nairajay@ iastate.edu.

This is an open access article distributed under the CC BY-NC-ND license (https://creativecommons.org/ licenses/by-nc-nd/4.0/).

https://doi.org/10.21273/HORTTECH04626-20 transplants. This flexibility in $\mathrm{RH}$ and temperature management is advantageous for small-scale growers who may not be able to tightly regulate the environmental conditions of a healing chamber.

Although the effects of air temperature have been examined, there has been no known work dedicated to examining the role of substrate temperature in grafted tomato transplant survival. Prior work involving tomato substrate and root-zone temperature modifications may be an indication of the potential role that managing substrate temperature can have in tomato graft healing. Hurewitz and Janes (1983) demonstrated that $30{ }^{\circ} \mathrm{C}$ was the optimal temperature for tomato transplant growth based on the response measured in plant fresh weight, dry weight, and leaf area. This optimum temperature was reaffirmed by McMichael and Burke (1998). However, Tindall et al. (1990) found that tomato shoot growth, plant height, and water use were optimized at a lower temperature of $25{ }^{\circ} \mathrm{C}$. It is expected that changes in substrate temperatures for grafted tomato transplants would be observed in air temperatures in corresponding healing chambers.

Because of the lack of information regarding how substrate temperatures could affect tomato graft healing, and because of the various recommendations for the management of air temperatures and light levels, we aimed to explore the effects of altering tomato root-zone temperatures while simultaneously assessing various durations of light exclusion. The design of light treatments was based on evolving recommendations for healing chamber management that have been previously outlined. Specifically, we were interested in the response of grafted tomato transplants under no light reduction in small-scale healing chambers. Our experimental design combined current small-scale grower practices, prior work involving healing chamber modifications, and alternative approaches to temperature and light management. We took a novel approach to graft transplant temperature management by comparing treatments placed on propagation mats compared with those kept in ambient conditions. We hypothesized that $4 \mathrm{~d}$ of light exclusion and the use of propagation heat mats would improve grafted tomato transplant survival and growth during the healing period.

\section{Materials and methods}

EXPERIMENTAL DESIGN. This study was conducted in the horticulture greenhouses at Iowa State University in Ames, IA. The experimental design was a randomized, complete, split plot design conducted using two repetitions over time with four blocks nested in each repetition. Heat was the whole plot factor (two levels) and dark was the subplot factor (three levels) for a total number of 24 experimental units within each repetition. Each experimental unit contained 36 individual grafted plants. Heat treatments were heat and no heat; the dark treatments were 0,4 , and $6 \mathrm{~d}$ of dark.

During the experiment, $1000-\mathrm{W}$ high-pressure sodium bulbs (AgroMax, Summerdale, AL) mounted in a fixture with reflectors (Maxima PLX; P.L. Light Systems, Beamsville, ON, Canada) with a $16-\mathrm{h}$ photoperiod $(0600$ to $2200 \mathrm{HR}$ ) provided supplemental light within the greenhouse. Temperature set points for the greenhouse were 20 to $22{ }^{\circ} \mathrm{C}(0600$ to $2200 \mathrm{HR})$ and 17 to $19^{\circ} \mathrm{C}(2200$ to $0600 \mathrm{HR}$ ). All environmental parameters within the greenhouse were managed by computer automation (Argus, Surrey, BC, Canada). The study was repeated two times in

\begin{tabular}{llll}
\hline $\begin{array}{l}\text { Units } \\
\text { To convert U.S. to SI, } \\
\text { multiply by }\end{array}$ & U.S. unit & SI unit & $\begin{array}{l}\text { To convert SI to U.S., } \\
\text { multiply by }\end{array}$ \\
\hline $\mathrm{l}$ & $\mathrm{cbar}$ & $\mathrm{kPa}$ & $\mathrm{l}$ \\
10.7639 & $\mathrm{fc}$ & $\mathrm{lx}$ & 0.0929 \\
0.3048 & $\mathrm{ft}$ & $\mathrm{m}$ & 3.2808 \\
2.54 & inch $(\mathrm{es})$ & $\mathrm{cm}$ & 0.3937 \\
25.4 & inch(es) & $\mathrm{mm}$ & 0.0394 \\
28.3495 & $\mathrm{oz}$ & $\mathrm{g}$ & 0.0353 \\
1 & $\mathrm{ppm}$ & $\mathrm{mg} \cdot \mathrm{L}^{-1}$ & 1 \\
$\left({ }^{\circ} \mathrm{F}-32\right) \div 1.8$ & ${ }^{\circ} \mathrm{F}$ & ${ }^{\circ} \mathrm{C}$ & $\left({ }^{\circ} \mathrm{C} \times 1.8\right)+32$
\end{tabular}


2017: from 20 Jan. to 3 Mar. and from 3 Mar. to 13 Apr.

HeAling CHAMBER DESIGN AND MANAGEMENT. The grafted transplants were grown in 606 standard inserts (STI-606-DP; T.O. Plastics, Clearwater, MN). Six sets of 606 standard insert packs were set together in a $2 \times 3$ configuration to mimic the layout of being set in a 1020 standard flat (STF-1020HW; T.O. Plastics). Transplants in all treatments were covered with clear humidity domes (length 21.5 inches $\times$ width 11 inches $\times$ height 2.1 inches; STF-1020-CLEAR-DOME; T.O. Plastics) until $7 \mathrm{~d}$ postgrafting.

To apply the whole plot factor of heat treatments, half of the healing chambers were placed on propagation mats (length 60 inches $\times$ width 22 inches; PM-9A; Pro-Grow Supply, Brookfield, WI) connected to a thermostat (Gro-control GC-4; ProGrow Supply) with a set-point of 80 ${ }^{\circ} \mathrm{F}$. The other half of healing chambers remained on the greenhouse bench in ambient conditions. The selection of the set-point of $80^{\circ} \mathrm{F}$ balanced previously referenced recommendations for healing chamber air temperatures (Johnson and Miles, 2011; Kubota et al., 2008; Rivard and Louws, 2011) and tomato transplant root-zone temperatures (Hurewitz and Janes, 1983; McMichael and Burke, 1998; Tindall et al., 1990).

Each set of whole plot (heat or no heat) treatments was placed on a section of insulation foam board (length $6 \mathrm{ft} \times$ width 24 inches $\times$ depth 1 inch; Scoreboard 124061; Dow, Midland, MI). This was performed to mediate temperatures among treatments and ensure equal distribution of heat through the heating mats. During graft healing, substrate moisture was regulated using capillary matting (length 54 inches $\times$ width 21 inches $\times$ thickness $1 / 16$ inches; 40 385; Gardener's Supply Company, Burlington, VT) placed on top of the insulation board. All 606 standard inserts were set directly on the capillary matting.

To test the effects of the number of days without light, three subplot (dark) treatments were assigned as follows: two-thirds of the experimental units were covered with an additional humidity dome painted completely black (Krylon; Sherwin-Williams, Cleveland, $\mathrm{OH}$ ) with an additional coat of aluminum paint (Krylon; Sherwin-Williams) to block all light for 4 or $6 \mathrm{~d}$. This design was based on a preliminary greenhouse study in 2016. The additional layer of aluminum paint was added to reflect light and avoid excess heat within the chambers. The healing chamber design and layout within the greenhouse are shown in Fig. 1. The light-blocking domes were removed at $\approx 1700$ HR on days 4 and 6 for each repetition of the study.

Plant material, grafting, and HeAling. 'Cherokee Purple' (Johnny's Selected Seeds, Winslow, ME) was selected as the scion because it represents an heirloom tomato that is commonly used by small-scale growers (Lang and Nair, 2019). 'RST-04-106-T' (DP Seeds, Yuma, AZ), was selected as the rootstock because it had been used in prior research in combination with 'Cherokee Purple' (Lang and Nair, 2019).

Scion and rootstock plugs were transplanted $12 \mathrm{~d}$ after seeding (DAS). Scions were transplanted to 72-cell trays (PL-72; T.O. Plastics). Rootstocks were transplants to 606 standard inserts, each filled with a soilless potting mix (Metro Mix 360; Sun Gro Horticulture, Agawam, MA). Before grafting, plants were watered as needed and fertilized twice using a water-soluble fertilizer $(15 \mathrm{~N}-2.2 \mathrm{P}-$ and Cal-Mag; Everris International, Geldermalsen, The Netherlands) with nitrogen $(\mathrm{N})$ at $150 \mathrm{ppm}$ concentration. Irrigation water was 12.4K; Peters Excel Multi-Purpose

reduced the day before grafting to prevent exudation of xylem sap from the cut rootstock stems (Buajaila et al., 2018).

Grafting occurred 21 DAS for both repetitions ( $10 \mathrm{Feb}$. and 24 Mar. 2017) when the stem diameters were appropriate for splice grafting. Tomatoes were grafted using the splice grafting method (Lee et al., 2010), as previously outlined by Lang and Nair (2019). Grafting was completed within 4.5 and 3.5 h for repetitions 1 and 2 , respectively. Plants were grafted by five trained individuals. To prevent the confounding factor of multiple grafters, each grafter placed an identifying sticker on each 606 standard insert pack they completed. The 606 standard insert packs completed by the same grafter were assigned uniformly across treatments within blocks. After completion of grafting, all plants were moved to the greenhouse for assignment to healing chamber treatments.

The day when grafting occurred was considered day 0 postgrafting. On days 1 through 5 , each healing chamber was briefly opened, and plants were misted daily using a hand-held spray bottle to aid in maintaining high $\mathrm{RH}$. On day 7 postgrafting, the clear humidity domes were removed from all treatments at $\approx 0800 \mathrm{HR}$, returning transplants to ambient greenhouse conditions. The transplants remained in the greenhouse until 21 and $19 \mathrm{~d}$ postgrafting for repetitions 1 and 2 of the experiment, respectively. The capillary

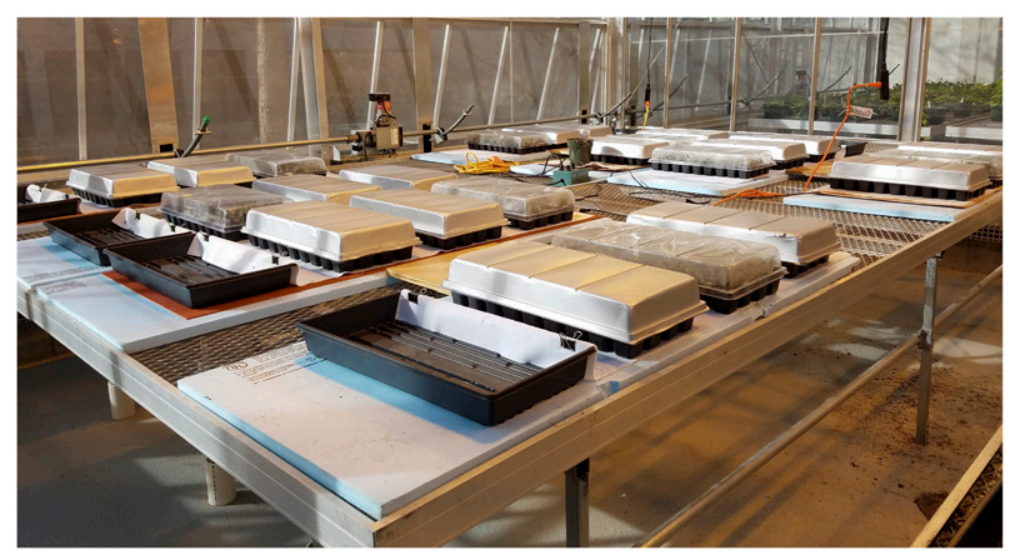

Fig. 1. Tomato transplants on day 0 postgrafting inside healing chambers that remained under light-blocking domes for 0,4 , or $6 \mathrm{~d}$. To test the effects of substrate temperature modifications, healing chambers were placed on propagation mats with a set point of $80^{\circ} \mathrm{F}\left(26.67^{\circ} \mathrm{C}\right)$ or remained on the greenhouse bench in ambient conditions. 
matting was used to maintain substrate moisture during the remainder of the study period. Plants were fertilized once before termination with the same water-soluble fertilizer described previously at a rate of 300 ppm N.

ENVIRONMENTAL MONITORING. Air temperature, $\mathrm{RH}$, and vapor pressure deficit (VPD) were recorded every 15 min by thermistors (DHT22; Adafruit Industries LLC, New York, NY) connected to a microcontroller (Mega 2560; Arduino, Somerville, MA). Substrate temperature was recorded every $15 \mathrm{~min}$ by soil-based thermocouples (DS18B20; Maxim Integrated Products, Sunnyvale, CA) connected to the same microcontroller mentioned previously. Light intensity was recorded every 15 min with data loggers (Hobo Pendant; Onset Computer Corp., Bourne, MA) placed on the substrate surface inside each healing chamber within all four blocks. Two additional data loggers were used to record general greenhouse conditions; the sensors were placed on the bench and collected light and temperature data.

Grafted plant survival. Graft survival was counted one time during the study modeled after the approach used by Masterson et al. (2016b). Plants were counted as having survived if the scion leaves were completely turgid, as defined by Johnson and Miles (2011). Data were collected on 12 and $11 \mathrm{~d}$ postgrafting for repetitions 1 and 2 of the experiment, respectively.

Plant growth parameters. Stem diameter was measured at the time of grafting and $14 \mathrm{~d}$ after grafting, on 24 Feb. and 7 Apr. 2017, for repetitions 1 and 2 of the experiment, respectively. The same six plants for each experimental unit were used for both measurement dates $(\mathrm{n}=144)$, and all plants measured were grafted by the same person. Stem diameter was measured using digital calipers (2YNC6 Westward; Grainger Inc., Burr Ridge, IL). The calipers were placed even with the top of the silicon grafting clip for both measurement dates to ensure the same place on the stem was being measured to calculate stem diameter relative growth (SDRG). SDRG was calculated as [(stem diameter $14 \mathrm{~d}$ after grafting stem diameter immediately after grafting) / (stem diameter immediately after grafting) $\times 100 \%](\mathrm{Hu}$ and Kleinhenz, 2015).

The experiment was ended on 3 Mar. and 13 Apr., and biomass collection occurred on these dates. Six plants from each treatment were destructively sampled for biomass $(\mathrm{n}=$ 144). Scion and rootstocks were separated at the graft union using a razor blade. All rootstocks were washed until no substrate remained. Individual scions and rootstocks were collected in labeled brown paper bags for drying. Biomass samples were placed in a drying oven (622; Hotpack, Philadelphia, PA) at $67^{\circ} \mathrm{C}$ for $3 \mathrm{~d}$. After all moisture had been removed, dried tissue was weighed using a 500-g scale (Scout Pro Balance; Ohaus Corporation, Parsippany, NJ).

Data ANALYSIS. Data were analyzed using PROC GLIMMIX in SAS (version 9.4; SAS Institute, Cary, NC). Environmental data were analyzed to show heat by dark interactions. There was a significant heat $x$ dark interaction for graft survival ( $P \leq 0.05)$, and data were analyzed accordingly. Remaining response variables had no heat $\times$ dark interactions; therefore, the analysis focused on the main effects of heat and dark. RH and VPD were arcsine-square root-transformed for analysis and then backtransformed for the presentation of means. An analysis of conditional residuals for all other response variables indicated no deviation from homogeneity or normality assumptions. All treatment means were separated using Tukey's honestly significant difference test $(\alpha=0.05)$. Additionally, an analysis of variance was performed for graft survival as affected by the grafter; the results were not significant for either repetition of the study $(P=0.69$ and $P=0.22$, respectively).

\section{Results}

Light InTENSITy. Healing chambers constructed with only clear domes ( $0 \mathrm{~d}$ of dark) had light entering the chamber each day and reached an average maximum light intensity of 35,391 lx during days 0 to 7 postgrafting. The chambers that were covered with light-blocking domes for either 4 or $6 \mathrm{~d}$ received no detectible light within the healing chambers during the respective treatment periods. After light-blocking domes were removed, the average maximum light intensity values through day 7 postgrafting were 37,200 and 38,837 lx within the chambers with 4 and 6 $\mathrm{d}$ of dark, respectively. Within the greenhouse, the average maximum light intensity at the bench level was 64,756 lx during the 7 - $d$ period postgrafting for the two repetitions of the experiment.

A I R A N D $S$ U B S T R A T E TEMPERATURE. Within the greenhouse, the air temperature ranged from 16 to $31{ }^{\circ} \mathrm{C}$, with an overall average air temperature of $22^{\circ} \mathrm{C}$ during the $7-\mathrm{d}$ period postgrafting for the two repetitions. During the 7d postgrafting period, there was an interaction between heat and dark treatments for average and maximum air temperatures (Table 1). Healing chambers subjected to the heat treatment had higher maximum air temperatures compared with chambers in ambient conditions (no heat) (Table 1). With the heat treatment, the 4-d dark treatment had a higher maximum air temperature than the $6-\mathrm{d}$ dark treatment (Table 1). There were no differences in the average and minimum air temperatures among dark treatments for healing chambers in the heat treatment (Table 1). For healing chambers in no-heat and 0-d dark treatment, there was an increase in the average and maximum air temperatures (Table 1). With the no-heat treatment, there were no differences in minimum air temperatures subjected to dark treatments (Table 1).

The substrate temperature pattern varied between heat and no-heat treatments during the 7 -d period postgrafting. The daily minimum substrate temperature occurred between 0000 and $0400 \mathrm{HR}$ each day for noheat treatments; however, during this same period, the substrate temperature with the heat treatment generally reached the daily maximum. There were no differences in the average, minimum, and maximum substrate temperatures among healing chambers subjected to the heat treatment (Table 1). With the no-heat treatment, there was an increase in the average substrate temperature in the 0 - $\mathrm{d}$ dark treatment compared with the 4- and 6-d dark treatments (Table 1). Minimum and maximum substrate temperatures were not different among healing chambers subjected to the no-heat treatment (Table 1). 
RH AND VPD. During the 7$\mathrm{d}$ postgrafting period, healing chambers subjected to the heat treatment had more constant $\mathrm{RH}$ compared with those subjected to the no-heat treatment; however, by day 5 postgrafting, there was a noticeable increase in daily $\mathrm{RH}$ variability among all treatments. There were no differences among the average, minimum, and maximum RH or VPD values for any heat treatment $\times$ dark treatment combinations (Table 2).

GrafTED PLANT SURVIVAL. There was an interaction between heat and dark main effects on grafted plant survival (Table 3). Grafted plant survival was greatest under $0 \mathrm{~d}$ of dark with both heat treatment and no-heat treatment. Survival of plants subjected to the heat treatment decreased from $96 \%$ to $45 \%$ as the dark treatments

Table 1. Effects of heat and dark treatment interactions on average, minimum, and maximum air and substrate temperatures for grafted tomato transplants from day 0 to 7 in a study of postgrafting healing methods conducted in a greenhouse in Ames, IA. ${ }^{\mathrm{z}}$

\begin{tabular}{|c|c|c|c|c|c|c|}
\hline \multirow[b]{2}{*}{ Dark $^{x}$} & \multicolumn{3}{|c|}{ Air temp $\left({ }^{\circ} \mathrm{C}\right)^{\mathrm{y}}$} & \multicolumn{3}{|c|}{ Substrate temp $\left({ }^{\circ} \mathrm{C}\right)$} \\
\hline & Avg & Min & Max & Avg & Min & Max \\
\hline & \multicolumn{6}{|c|}{ Heat $^{w}$} \\
\hline 0 & 28.4 & 19.9 & $39.1 \mathrm{ab}^{\mathrm{v}}$ & 32.7 & 23.3 & 41.2 \\
\hline 4 & 29.9 & 19.7 & $41.5 \mathrm{a}$ & 33.6 & 21.0 & 45.2 \\
\hline 6 & 28.4 & 19.6 & $34.9 \mathrm{~b}$ & 33.6 & 22.1 & 45.6 \\
\hline \multirow[t]{2}{*}{$P^{\mathrm{u}}$} & 0.18 & 0.90 & 0.006 & 0.63 & 0.26 & 0.46 \\
\hline & \multicolumn{6}{|c|}{ No heat } \\
\hline 0 & $22.8 \mathrm{a}$ & 15.9 & $37.2 \mathrm{a}$ & $20.4 \mathrm{a}$ & 15.7 & 27.3 \\
\hline 4 & $20.7 \mathrm{~b}$ & 16.2 & $28.7 \mathrm{~b}$ & $19.3 \mathrm{~b}$ & 15.6 & 27.7 \\
\hline 6 & $20.6 \mathrm{~b}$ & 16.0 & $28.8 \mathrm{~b}$ & $19.0 \mathrm{~b}$ & 15.7 & 24.5 \\
\hline$P$ & 0.02 & 0.49 & 0.009 & 0.01 & 0.97 & 0.06 \\
\hline
\end{tabular}

${ }^{\mathrm{z}}$ Data of days 0 to 7 postgrafting across two replications over time (10 Feb.-17 Feb. and 24 Mar.-31 Mar. 2017) were averaged

$\mathrm{y}\left(1.8 \times{ }^{\circ} \mathrm{C}\right)+32={ }^{\circ} \mathrm{F}$.

${ }^{\mathrm{x}}$ Dark indicates the number of days postgrafting when light was excluded from the healing chamber.

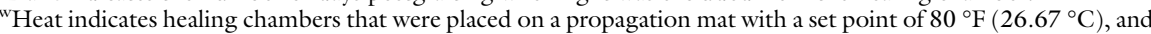

"no heat" indicates healing chambers that remained on the greenhouse bench in ambient conditions.

"Means followed by the same letter within either "heat" or "no heat" and the same column are not different according to Tukey's honestly significant difference test $(\alpha=0.05)$

${ }^{\mathrm{u}}$ Data were analyzed using PROC GLIMMIX in SAS (version 9.4; SAS Institute, Cary, NC).

Table 2. Effect of heat and dark treatment interactions on average, minimum, and maximum relative humidity (RH) and vapor pressure deficit (VPD) for grafted tomato transplants from day 0 to 7 in a study of postgrafting healing methods conducted in a greenhouse in Ames, IA. ${ }^{z}$

\begin{tabular}{|c|c|c|c|c|c|c|}
\hline \multirow[b]{2}{*}{ Dark $^{x}$} & \multicolumn{3}{|c|}{ RH (\%) } & \multicolumn{3}{|c|}{$\operatorname{VPD}(k P a)^{y}$} \\
\hline & Avg & Min & Max & Avg & Min & Max \\
\hline & \multicolumn{6}{|c|}{ Heat $^{\mathrm{w}}$} \\
\hline 0 & 95.7 & 38.8 & 98.9 & 0.40 & 0.00 & 3.46 \\
\hline 4 & 96.5 & 46.5 & 99.9 & 1.83 & 0.20 & 4.47 \\
\hline 6 & 91.7 & 31.7 & 99.9 & 0.21 & 0.00 & 2.06 \\
\hline$P^{v}$ & 0.16 & 0.52 & 0.72 & 0.31 & 0.41 & 0.46 \\
\hline & \multicolumn{6}{|c|}{ No heat } \\
\hline 0 & 92.2 & 32.6 & 95.7 & 0.49 & 0.02 & 3.02 \\
\hline 4 & 89.5 & 27.6 & 96.5 & 0.62 & 0.25 & 2.59 \\
\hline 6 & 93.0 & 44.6 & 91.7 & 0.93 & 0.27 & 3.34 \\
\hline$P$ & 0.10 & 0.06 & 0.41 & 0.94 & 0.63 & 0.80 \\
\hline
\end{tabular}

${ }^{\mathrm{z}}$ Data of days 0 to 7 postgrafting across two replications over time (10 Feb.-17 Feb. and 24 Mar.-31 Mar. 2017) were averaged.

$\mathrm{y}_{1} \mathrm{kPa}=1 \mathrm{cbar}$

"Dark" indicates the number of days postgrafting when light was excluded from the healing chamber.

w"Heat" indicates healing chambers that were placed on a propagation mat with a set point of $80{ }^{\circ} \mathrm{F}\left(26.67^{\circ} \mathrm{C}\right)$, and "no heat" indicates healing chambers that remained on the greenhouse bench in ambient conditions.

'Data were analyzed using PROC GLIMMIX in SAS (version 9.4; SAS Institute, Cary, NC). All data were arcsinesquare root-transformed for analysis and then back-transformed for presentation of means.

increased from 0 to $6 \mathrm{~d}$ (Table 3). With the no-heat treatment, grafted plant survival decreased from $97 \%$ to $82 \%$ as the dark treatments increased from 0 to $6 \mathrm{~d}$ (Table 3 ).

Plant growth parameters. There were no interactions among heat and dark main effects on the remaining plant growth parameters of SDRG, stem diameter, or scion and rootstock biomasses (Table 4). Both SDRG and stem diameter decreased as the number of days of dark increased (Table 4). SDRG was 1.7times greater for plants subjected to the 0 -d dark treatment compared with the 4- and 6-d dark treatments (Table 4). Heat had no effect on SDRG or stem diameter (Table 4). The dark and heat treatments did not affect scion and rootstock biomasses (Table 4).

\section{Discussion}

This study tested the effects of substrate heat application and the number of days without light for the healing of grafted tomato transplants. Controlling the number of days of blocked light was easily achieved using painted domes removed on days 4 and 6 postgrafting. However, controlling the temperature with the propagation mats proved less effective due to the lack of precision within the thermostats used for the study. Furthermore, the heat treatment was detrimental to plant survival under 4 and $6 \mathrm{~d}$ of darkness. The 0 -d dark treatment resulted in the highest plant survival with and without added heat (96\% and $97 \%$, respectively).

The inclusion of a 6-d dark treatment proved to be extreme, and our results for both 4 and $6 \mathrm{~d}$ of light exclusion confirm the recommendation by Buajaila et al. (2018) that full light exclusion should no longer be a recommendation for healing of grafted tomato transplants. Our study is unique because of the use of a treatment with no light reduction. Light intensity within the healing chambers in the 0 -d dark treatment was much higher than that reported by other studies. Kubota et al. (2008) recommended a target photosynthetic photo flux density (PPFD) of 100 $\mu \mathrm{mol} \cdot \mathrm{m}^{-2} \cdot \mathrm{s}^{-1}$. When our data were converted from $\mathrm{lx}$ to $P P F D$, for comparison, the average PPFD under $0 \mathrm{~d}$ of dark was $\approx 430 \mu \mathrm{mol} \cdot \mathrm{m}^{-2} \cdot \mathrm{s}^{-1}$. Additionally, the average light 
intensity inside the 0 - $\mathrm{d}$ dark chamber in our study was approximately fivetimes greater than the highest light treatment $(50 \%$ available light $)$ used by Buajaila et al. (2018). Although the authors reported that survival rates of grafted tomato, eggplant, and pepper were highest under the $50 \%$ available light treatment in

Table 3. Mean percent survival of grafted tomato transplants as a function of heat and dark interactions in a study of postgrafting healing methods conducted in a greenhouse in Ames, IA. ${ }^{\mathrm{z}}$

\begin{tabular}{llc}
\hline & \multicolumn{2}{c}{ Survival (\%) } \\
\cline { 2 - 3 } Dark $^{\mathbf{y}}$ & Heat $^{\mathbf{w}}$ & No heat \\
\hline 0 & $96 \mathrm{a}^{\mathrm{v}}$ & $97 \mathrm{a}$ \\
4 & $63 \mathrm{~b}$ & $86 \mathrm{~b}$ \\
6 & $45 \mathrm{c}$ & $82 \mathrm{~b}$ \\
$P^{\mathrm{u}}$ & $<0.0001$ & 0.001 \\
\hline
\end{tabular}

${ }^{\mathrm{z}}$ There was a significant interaction between the main effects of heat and dark $(P=0.04)$.

${ }^{y}$ Mean percent survival of 'Cherokee Purple' scion grafted to 'RST-04-106-T' rootstocks on 12 and 11 d postgrafting for repeats one and two, respectively.

"Dark" indicates the number of days postgrafting when light was excluded from the healing chamber. w"Heat" indicates healing chambers that were placed on a propagation mat with a set point of $80{ }^{\circ} \mathrm{F}$ $\left(26.67^{\circ} \mathrm{C}\right)$, and "no heat" indicates healing chambers that remained on the greenhouse bench in ambient conditions.

${ }^{\mathrm{v}}$ Means followed by the same letter within the same column are not different according to Tukey's honestly significant difference test $(\alpha=0.05)$.

"Data were analyzed using PROC GLIMMIX in SAS (version 9.4; SAS Institute, Cary, NC). combination with $100 \% \mathrm{RH}$, they did not specifically report the mean survival of tomatoes under these conditions (Buajaila et al., 2018).

We observed a consistent pattern of the substrate temperature exceeding the thermostat setting of $80^{\circ} \mathrm{F}$ in healing chambers placed on the propagation mats, especially during the nighttime hours when the propagations mats switched on more frequently. During this same period, the no-heat treatments were at their minimum temperature during the $24-\mathrm{h}$ period. The average substrate temperature with the heat treatment was near $33^{\circ} \mathrm{C}$, and this exceeded the recommended root-zone temperature indicated by past research (Hurewitz and Janes, 1983; McMichael and Burke, 1998; Tindall et al., 1990), and the maximum temperatures greatly exceeded the optimum target. With the no-heat treatment, the average substrate temperature was $\approx 10{ }^{\circ} \mathrm{C}$ below the optimum level.

Information regarding the role of substrate temperature in grafted plant healing is not readily available; therefore, it is difficult to compare our research to prior work. Furthermore, due to our research design, it is difficult to uncouple the effects of air temperature from soil temperature. Increased root and shoot biomass may have been one indicator of the effects of increased substrate temperatures (Hurewitz and Janes, 1983; Tindall et al., 1990), but we did not observe differences in either response variable to substantiate this assumption.

The average air temperature inside healing chambers with the heat treatment was near the recommended range for grafted tomato transplant healing, but the maximum temperature greatly exceeded those reported by other studies (Buajaila et al., 2018; Johnson and Miles, 2011; Masterson et al., 2016b). The average air temperature within healing chambers with the no-heat treatment was on the lower end of the range currently recommended; however, in general, it was comparable to those of prior studies (Buajaila et al., 2018; Johnson and Miles, 2011; Masterson et al., 2016b). Full sun conditions provided under the 0-d dark treatment, even in the absence of supplemental heat from a propagation mat, led to a maximum air temperature of $37^{\circ} \mathrm{C}$ within the healing chamber. The maximum temperatures in the healing chambers with the heat treatment were similar with 0 - and 4-d dark treatments, which was counter to the expectation that the chambers receiving full light would have had higher temperatures. This may have been due, in part, to the level of light entering the healing chamber when the light-blocking dome was removed from the 4 -d dark

Table 4. Main effects of dark and heat treatments on plant growth parameters [stem diameter relative growth (SDRG), stem diameter, scion biomass, and rootstock biomass] of grafted tomato transplants in a study of postgrafting healing methods conducted in a greenhouse in Ames, IA. ${ }^{z}$

\begin{tabular}{|c|c|c|c|c|}
\hline Treatment & SDRG $(\%)^{\mathrm{y}}$ & Stem diam $(\mathrm{mm})^{\mathrm{x}}$ & Scion biomass $(\mathrm{g})^{\mathrm{w}}$ & Rootstock biomass $(\mathrm{g})^{\mathrm{w}}$ \\
\hline \multicolumn{5}{|l|}{$\operatorname{Dark}(\mathrm{D})^{\mathrm{v}}$} \\
\hline 0 & $53 \mathrm{a}^{\mathrm{u}}$ & $3.6 \mathrm{a}$ & 0.34 & 0.09 \\
\hline 4 & $36 \mathrm{~b}$ & $3.2 \mathrm{~b}$ & 0.34 & 0.08 \\
\hline 6 & $28 \mathrm{~b}$ & $2.9 \mathrm{c}$ & 0.29 & 0.07 \\
\hline$P^{t}$ & $<0.0001$ & $<0.0001$ & 0.06 & 0.07 \\
\hline$P$ & 0.28 & 0.08 & 0.10 & 0.23 \\
\hline \multicolumn{5}{|l|}{$\mathrm{D} \times \mathrm{H}$} \\
\hline$P$ & 0.69 & 0.62 & 0.15 & 0.70 \\
\hline $\begin{array}{l}\text { "Cherokee Pur } \\
\text { "SDRG was calc } \\
\text { xStem diameter } \\
\text { "Biomass was c } \\
\text { "“Dark" indicat } \\
\text { "Means followe } \\
\text { tData were anal } \\
\text { "c"Heat" indicat } \\
\text { greenhouse ben }\end{array}$ & $\begin{array}{l}\text { were grafted to 'RS' } \\
\text { (stem diameter } 14 \mathrm{~d} \\
\text { red } 14 \mathrm{~d} \text { after grafti } \\
\text { and } 19 \mathrm{~d} \text { postgrafti } \\
\text { ber of days postgraf } \\
\text { me letter within eith } \\
\text { PROC GLIMMIX } \\
\text { hambers that were } \\
\text { ent conditions. }\end{array}$ & $\begin{array}{l}\text { rootstocks. } \\
\text { ng - stem diameter immed } \\
\text { eb. and } 7 \text { Apr. } 2017 \text { for rep } \\
\text { ats one and two, respectivel } \\
\text { ight was excluded from the } \\
\text { D or H and the same colur } \\
\text { ion } 9.4 \text {; SAS Institute, Car } \\
\text { propagation mat with a set }\end{array}$ & $\begin{array}{l}\text { rafting) / (stem diameter im } \\
\mathrm{d} \text { two, respectively }(1 \mathrm{~mm}= \\
\text { d } 13 \text { Apr. 2017). } 1 \mathrm{~g}=0.0 \\
\text { mber. } \\
\text { ifferent according to Tukey's } \\
{ }^{\circ} \mathrm{F}\left(26.67^{\circ} \mathrm{C}\right) \text {. "No heat" in }\end{array}$ & $\begin{array}{l}\text { ter grafting }) \times 100 \%] \text {. } \\
\text { nificant difference test }(\alpha=0.05) \text {. } \\
\text { g chambers that remained on the }\end{array}$ \\
\hline
\end{tabular}


treatment in combination with the supplemental heat.

The VPDs in our study were much higher than those found by Johnson and Miles (2011). Additionally, the RH within our chambers was much higher than the $\mathrm{RH}$ reported in recent studies by Johnson and Miles (2011) and Masterson et al. (2016b). However, our reported values align with recent $\mathrm{RH}$ values reported by Buajaila et al. (2018) and Wei et al. (2018). Our chambers, which were smaller compared with many designs, had reduced air volume within the closed system. Johnson and Miles (2011) suggested that minimizing healing chamber dimensions would be beneficial to decrease the ratio of the air volume to the water volume, thus easing maintenance of high $\mathrm{RH}$ and minimizing evapotranspiration from the scion leaves. Overall, the design and maintenance of our healing chambers resulted in $\mathrm{RH}$ values that align with the most current recommendations to maintain high $\mathrm{RH}$ to optimize grafted plant survival.

Our reported plant survival rates of $96 \%$ and $97 \%$ in $0 \mathrm{~d}$ of dark in combination with heat and no-heat treatments, respectively, are comparable to the grafted tomato survival rates of $98 \%$ found by Johnson and Miles (2011) and 91\% to 94\% found at one location during research conducted by Masterson et al. (2016b). It is difficult to make direct comparisons of plant survival rates because our chamber designs were different from those used by the two previously stated studies. However, Buajaila et al. (2018) found an average plant survival rate of $95 \%$ in a chamber with $50 \%$ available light and $100 \% \mathrm{RH}$; this is the closest comparison with our healing chamber design. Masterson et al. (2016b) found that survival rates of transplants inside a plastic chamber, without a humidifier, covered with a $55 \%$ shadecloth were $95 \%$ and $78 \%$ at two different trial locations. However, the RH values inside the chambers at each location (Masterson et al., 2016b) were up to $40 \%$ lower than the RH reported for our healing chambers.

Both SDRG and stem diameter were lower with the 4- and 6-d dark treatments, indicating that the length of photosynthesis suppression was detrimental to graft healing (Bie et al., 2017). Providing conditions to maximize photosynthetic activity as early as possible postgrafting may be important for compensating for suppressed activity during the initial graft union formation (Nobuoka et al., 2005). A higher SDRG, which leads to increased stem diameters at the time of planting, could be advantageous for continued transplant success after field planting (Bausher, 2013; Oda et al., 2005).

\section{Conclusion}

Our methods tested the recommendations for healing chamber management, and our findings demonstrate that these recommendations can be adjusted. Although we advise against the immediate adoption of propagation mat placement under healing chambers, there is an opportunity to explore alternative levels of substrate temperature modifications in combination with varying levels of light exclusion for grafted tomato transplant production. The magnitude of success for tomato transplant survival under full light conditions within our study was surprising, and has led us to recommend that this practice should be evaluated in multiple regions of the United States. There is a possibility that any level of light exclusion may not be necessary when RH and temperature are optimized during tomato graft healing. Overall, future research should continue to investigate low-input healing chamber designs and management protocols that improve small-scale vegetable operations.

\section{Literature cited}

Albacete, A., C. Martínez-Andújar, A. Martínez-Pérez, A.J. Thompson, I.C. Dodd, and F. Pérez-Alfocea. 2015. Unravelling rootstock $\times$ scion interactions to improve food security. J. Expt. Bot. 66:2211-2226.

Barrett, C.E., X. Zhao, and A.W. Hodges. 2012. Cost benefit analysis of using grafted transplants for root-knot nematode management in organic heirloom tomato production. HortTechnology 22:252-257.

Buajaila, F.A., P. Devi, and C.A. Miles. 2018. Effect of environment on survival of eggplant, pepper, and tomato in a smallscale healing chamber. HortTechnology 28:668-675.

Bausher, M.G. 2013. Graft angle and its relationship to tomato plant survival. HortScience 48:34-36.
Bie, Z., M.A. Nawaz, Y. Huang, J.-M. Lee, and G. Colla. 2017. Introduction to vegetable grafting, p. 1-21. In: G. Colla, F. Perez-Alfocea, and D. Schwarz (eds.). Vegetable grafting: Principles and practices. CAB International Publishing, Wallingford, UK.

Grieneisen, M.L., B.J. Aegerter, S.C. Stoddard, and M. Zhang. 2018. Yield and fruit quality of grafted tomatoes, and their potential for soil fumigant use reduction. A meta-analysis. Agron. Sustain. Dev. 38:39.

Hartmann, H.T., D.E. Kester, F.T. Davies, Jr., and R.L. Geneve. 2010. Hartmann \& Kester's plant propagation: Principles and practices. 8th ed. Prentice Hall, Upper Saddle River, NJ.

$\mathrm{Hu}$, B. and M.D. Kleinhenz. 2015. Selecting rootstock and scion varieties for organic grafted tomato production. Ceres Trust Final Report. 27 Aug. 2020. $<$ https://cerestrust.org/selectingrootstock-and-scion-varieties-for-organicgrafted-tomato-production $/>$.

Hurewitz, J. and H.W. Janes. 1983. Effect of altering the root-zone temperature on growth, translocation, carbon exchange rate, and leaf starch accumulation in the tomato. Plant Physiol. 73:46-50.

Johnson, S.J. and C.A. Miles. 2011. Effect of healing chamber design on the survival of grafted eggplant, tomato, and watermelon. HortTechnology 21:752758.

Kubota, C., M.A. McClure, N. KokalisBurelle, M.G. Bausher, and E.N. Rosskopf. 2008. Vegetable grafting: History, use, and current technology status in North America. HortScience 43:16641669.

Lang, K.M. and A. Nair. 2019. Effect of tomato rootstock on hybrid and heirloom tomato performance in a Midwest high tunnel production system. HortScience 54:840-845

Lee, J.M., C. Kubota, S.J. Tsao, Z. Bie, P.H. Echevarria, L. Morra, and M. Oda. 2010. Current status of vegetable grafting: Diffusion, grafting techniques, automation. Scientia Hort. 127:93-105.

Masterson, S.A., M.M. Kennelly, R.R. Janke, and C.L. Rivard. 2016a. Microclimate and scion leaf removal to improve the success of grafted tomato seedlings. HortTechnology 26:261-269.

Masterson, S.A., M.M. Kennelly, R.R. Janke, and C.L. Rivard. 2016b. Scion shoot removal and rootstock cultivar affect vigor and early yield of grafted tomatoes grown in high tunnels in the central United States. HortTechnology 26:399-408. 
McMichael, B.L. and J.J. Burke. 1998. Soil temperature and root growth. HortScience 33:947-951.

Meyer, L. 2016. Grafting to increase high tunnel tomato productivity in the central United States, Kansas State Univ., Manhattan, M.S. Thesis.

Meyer, L.J., M.M. Kennelly, E.D. Pliakoni, and C.L. Rivard. 2017. Leaf removal reduces scion adventitious root formation and plant growth of grafted tomato. Scientia Hort. 214:147-157.

Nobuoka, T., T. Nishimoto, and K. Toi. 2005. Wind and light promote graft-take and growth of grafted tomato seedlings. J. Jpn. Soc. Hort. Sci. 74:170-175.
Oda, M., M. Maruyama, and G. Mori. 2005. Water transfer at graft union of tomato plants grafted onto Solanum rootstocks. J. Jpn. Soc. Hort. Sci. 74:458463.

Rivard, C.L. and F.J. Louws. 2008. Grafting to manage soilborne diseases in heirloom tomato production. HortScience 43:2104-2111.

Rivard, C.L. and F.J. Louws. 2011. Tomato grafting for disease resistance and increased productivity. Sustainable Agr. Res. Educ. (SARE) Factsheet GS05-046.

Rysin, O., C.L. Rivard, and F.J. Louws. 2015. Is vegetable grafting economically viable in the United States: Evidence from four different tomato production systems. Acta Hort. 1086:79-86.

Rysin, O. and F.J. Louws. 2015. Decision tool for growers to evaluate economic impact of grafting technology adoption: An application to open-field conventional tomato production. HortTechnology 25: 132-138.

Tindall, J.A., H.A. Mills, and D.E. Radcliffe. 1990. The effect of root zone temperature on nutrient uptake of tomato. J. Plant Nutr. 13:939-956.

Wei, H., S. Muneer, A. Manivannan, Y. Liu, J.E. Park, and B.R. Jeong. 2018. Slight vapor deficit accelerates graft union healing of tomato plug seedling. Acta Physiol. Plant. 40:147. 